www.nature.com/pj

\title{
Self-oscillating core/shell microgels: effect of a crosslinked nanoshell on autonomous oscillation of the core
}

\author{
Daisuke Suzuki ${ }^{1}$ and Ryo Yoshida ${ }^{2,3}$ \\ We reported the effects of crosslinked nanoshells covering self-oscillating microgels on their oscillatory behaviors. We carried out \\ seeded precipitation polymerization of $\boldsymbol{N}$-substituted acrylamide derivatives using preformed, self-oscillating microgels as cores. \\ The core/shell microgels obtained were characterized by dynamic light scattering. Oscillating behaviors were characterized by \\ changes in optical transmittance. In addition, the characteristics (that is, induction period, oscillating period and waveform) \\ of the oscillation of the core/shell microgels were compared with that of the parent core microgel to clarify the effect of the \\ addition of a nanoshell on the autonomous oscillating behaviors of microgels.
}

Polymer Journal (2010) 42, 501-508; doi:10.1038/pj.2010.28; published online 21 April 2010

Keywords: core/shell microgel; dynamic light scattering; $N$-substituted acrylamide; oscillating microgel; oscillating reaction; seeded polymerization

\section{INTRODUCTION}

Soft polymer microgels, which have a network structure that swells in an aqueous solution, have attracted a lot of attention in material science because of their stimulus-sensitive properties. The microgels undergo a volume phase transition as a result of a change in temperature, ${ }^{1} \mathrm{pH},{ }^{2}$ ionic strength, ${ }^{3}$ light $^{4}$ and so on. In many cases, microgels are composed of poly( $N$-isopropylacrylamide) (pNIPAm), which is a typical thermosensitive polymer with a lower critical solution temperature of around $31^{\circ} \mathrm{C} .^{5,6}$

PNIPAm-based microgels can be functionalized by constructing nanocomposites with inorganic nanoparticles ${ }^{7-10}$ for application in more complex biotechnologies and nanotechnologies (for example, drug delivery, ${ }^{11,12}$ chemical/biological separation ${ }^{13,14}$ and photonic crystals $^{15-18}$. In addition, we reported that microgels can show selfoscillation, ${ }^{19-22}$ coupled with the Belousov-Zhabotinsky (BZ) reaction, ${ }^{23}$ which is an autonomous and periodic chemical reaction. We found that self-oscillating microgels show not only autonomous swelling/deswelling oscillation but also autonomous flocculating/dispersing oscillation near the volume phase transition temperature (VPTT) of the microgels. ${ }^{19}$ In addition, it became clear that volume oscillation is controlled by crosslinked network structures (that is, the BZ reaction of crosslinked microgels shows a longer duration of refractory state and a shorter duration of resting state than that of the bulk solution of the $\mathrm{BZ}$ reaction). ${ }^{20,21}$
In this study, we investigated the effects of a crosslinked nanoshell covering self-oscillating microgels on their oscillatory behavior (Figure 1). One of the problems of self-oscillating microgels was their flocculation above their VPTT, ${ }^{19}$ which made their use difficult in specific applications. It could be assumed that the introduction of the nanoshell made self-oscillating microgels colloidally stable even above their VPTT when the nanoshell showed steric hindrance. In addition, core/shell structured microgels can exhibit multiple responsiveness and core- or shell-specific functionalities. Herein, we carried out seeded precipitation polymerization ${ }^{16,24-28}$ of $\mathrm{N}$-substituted acrylamide derivatives using self-oscillating microgels as cores. The microgels obtained were characterized by dynamic light scattering. Their self-oscillating behaviors were then detected by changes in optical transmittance. Here the characteristics (that is, induction period, oscillating period and waveform) of the self-oscillation of the core/ shell microgels are compared with that of the parent core microgel to clarify the effect of nanoshell addition on the autonomous oscillatory behavior of microgels.

\section{EXPERIMENTAL PROCEDURE \\ Materials}

Unless stated otherwise, all reagents were purchased from Wako Pure Chemical Industries (Osaka, Japan). N-isopropylacrylamide (NIPAm, Sigma-Aldrich, Tokyo, Japan) was recrystallized from hexanes and dried in vacuo before use.

\footnotetext{
${ }^{1}$ International Young Researchers Empowerment Center, Shinshu University, Ueda, Nagano, Japan; ${ }^{2}$ Department of Materials Engineering, Graduate School of Engineering, University of Tokyo, Bunkyo-ku, Tokyo, Japan and ${ }^{3}$ PRESTO, Japan Science and Technology Agency, Saitama, Japan

Correspondence: Dr D Suzuki, International Young Researchers Empowerment Center, Shinshu University, 3-15-1, Tokida, Ueda, Nagano 386-8567, Japan.

E-mail: d_suzuki@shinshu-u.ac.jp or Professor R Yoshida, Department of Materials Engineering, Graduate School of Engineering, University of Tokyo, Bunkyo-ku, Tokyo 113-8656, Japan.

E-mail: ryo@cross.t.u-tokyo.ac.jp

Received 26 January 2010; revised 4 March 2010; accepted 6 March 2010; published online 21 April 2010
} 


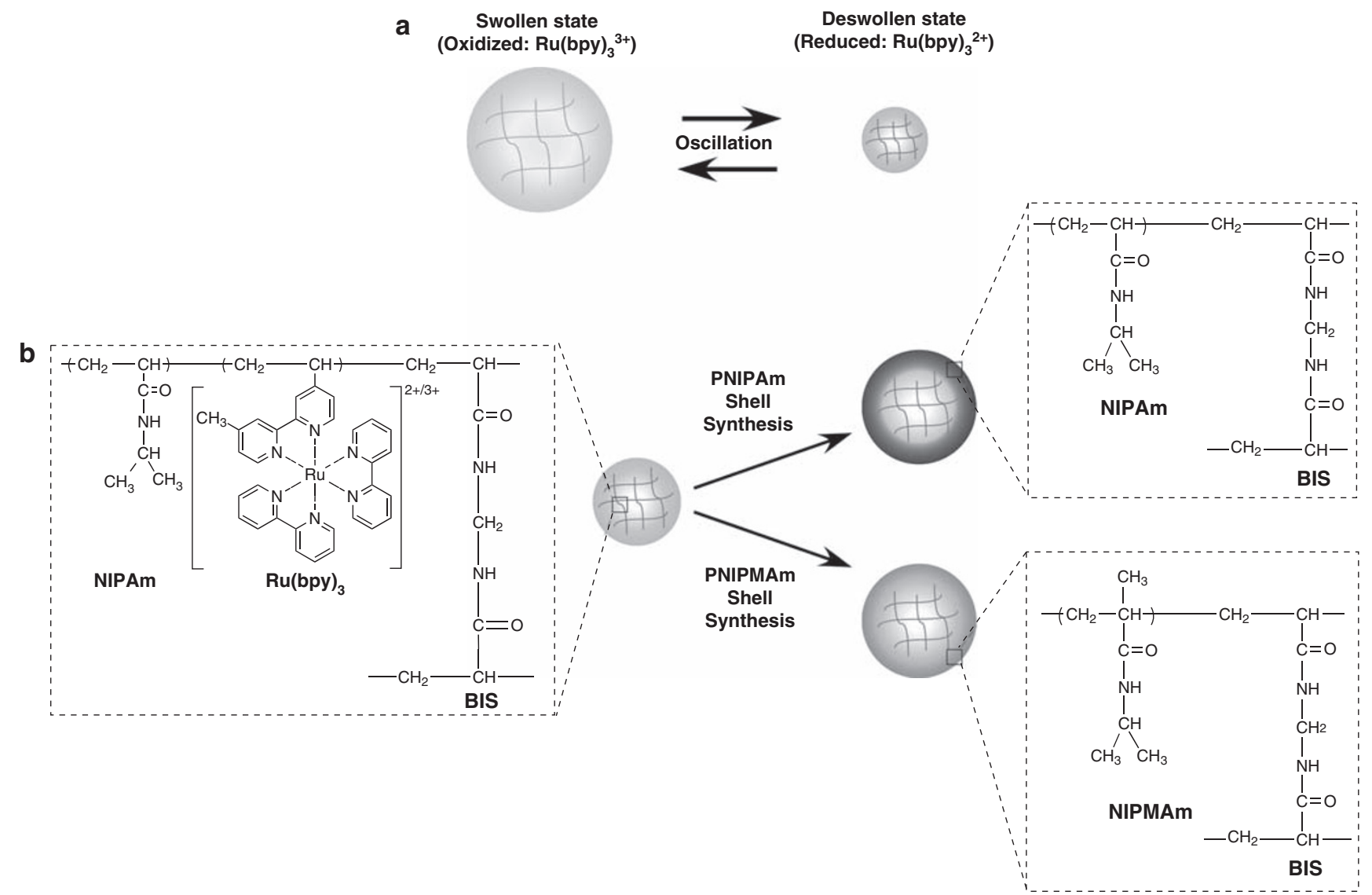

Figure 1 (a) Autonomous swelling/deswelling oscillation of microgels. (b) Chemical structures of core and core/shell microgels. A full color version of this figure is available at the Polymer Journal journal online.

$\mathrm{N}$-isopropylmethacrylamide (NIPMAm, Sigma-Aldrich) was used as received. The crosslinker $N, N^{\prime}$-methylenebis(acrylamide) (BIS, Kanto Chemical, Tokyo, Japan) and the initiator azobis(amidinopropane) dihydrochloride (V-50) were used as received. Ruthenium(II) (4-vinyl-4'-methyl-2,2'-bipyridine)bis(2,2'bipyridine)bis(hexafluorophosphate) $\left[\mathrm{Ru}(\mathrm{bpy})_{3}\right.$ monomer $]$ was synthesized according to the previous work. ${ }^{29,30}$ Malonic acid, sodium bromate $\left(\mathrm{NaBrO}_{3}\right.$, Kanto Chemical), nitric acid $\left(\mathrm{HNO}_{3}\right.$, Kanto Chemical), cerium(IV) sulfate tetrahydrate $\left[\mathrm{Ce}\left(\mathrm{SO}_{4}\right)_{2} 4 \mathrm{H}_{2} \mathrm{O}\right]$, cerium(III) sulfate $n$-hydrate $(n=5)\left[\mathrm{Ce}_{2}\left(\mathrm{SO}_{4}\right)_{3}\right.$ $\left.5 \mathrm{H}_{2} \mathrm{O}\right]$ and sodium chloride $(\mathrm{NaCl})$ were all used as received. Water for all reactions, as well as for solution preparation and polymer purification, was first distilled and then ion exchanged.

\section{Synthesis of core microgel}

The core microgels of $\mathrm{Ru}(\mathrm{bpy})_{3}$-copolymerized pNIPAm were synthesized by surfactant-free aqueous radical precipitation polymerization as previously reported. ${ }^{19-22}$ A mixture of NIPAm (97 mol\%, $3.292 \mathrm{~g}$ ), Ru(bpy) 3 (1 mol\%, $0.270 \mathrm{~g})$, BIS $(2 \mathrm{~mol} \%, 0.092 \mathrm{~g})$ and water $(195 \mathrm{ml})$ was poured into a $300 \mathrm{ml}$ three-neck, round-bottom flask equipped with a stirrer, a condenser and a nitrogen gas inlet. Under a stream of nitrogen to purge oxygen and with constant stirring, the solution was heated in an oil bath to $70^{\circ} \mathrm{C}$. After the solution was stabilized for $1 \mathrm{~h}$, the V-50 initiator $(0.108 \mathrm{~g})$ was dissolved in $5 \mathrm{ml}$ of water and added to the flask to start polymerization, which then continued for $6 \mathrm{~h}$. After polymerization, the dispersion was cooled to room temperature. The microgels were purified by centrifugation/redispersion with water four times using a relative centrifugal force of $52490 \mathrm{~g}$ and by daily changes of water by means of dialysis for 1 week.

\section{Synthesis of core/shell microgel}

For shell synthesis, core microgels $(0.4 \mathrm{~g})$ were dispersed in a $5 \mathrm{~mm} \mathrm{NaCl}$ solution $(175 \mathrm{ml})$ and placed in a $300-\mathrm{ml}$ three-neck, round-bottom flask equipped with a stirrer, a condenser and a nitrogen gas inlet. Under a stream of nitrogen to purge oxygen and with constant stirring, the solution was heated to $70^{\circ} \mathrm{C}$. After $50 \mathrm{~min}$, a $20 \mathrm{ml}$ solution of NIPAm $(98 \mathrm{~mol} \%, 0.888 \mathrm{~g})$ and BIS ( $2 \mathrm{~mol} \%, 0.024 \mathrm{~g})$ or NIPMAm $(98 \mathrm{~mol} \%, 0.998 \mathrm{~g})$ and BIS ( $2 \mathrm{~mol} \%, 0.024 \mathrm{~g})$ was added to the flask. After $10 \mathrm{~min}$, polymerization was initiated by injecting $5 \mathrm{ml}$ of V-50 $(0.108 \mathrm{~g})$ solution. The reaction was maintained at $70^{\circ} \mathrm{C}$ for $4 \mathrm{~h}$. The core/shell microgels were purified by centrifugation/redispersion with water four times using a relative centrifugal force of $52490 \mathrm{~g}$ and by daily changes of water by means of dialysis for 1 week.

\section{Characterization}

The size and polydispersity indices of microgels were determined by dynamic light scattering (Zetasizer 3000HSA, Malvern Instruments, Kobe, Japan). Polydispersity indice values were calculated from the cumulant analysis as defined in ISO13321. Diluted microgel dispersions were analyzed in a quartz cuvette (microgel concentration: $0.005 \mathrm{wt} \%$ ). The samples were allowed to equilibrate at the desired temperature for $10 \mathrm{~min}$ before data collection. Scattered light was collected at $90^{\circ}$. $\mathrm{NaCl}$ was then used to adjust each solution to $1 \mathrm{~mm}$ total ion concentration. Moreover, to maintain the reduced $\mathrm{Ru}^{\mathrm{II}}$ and oxidized $\mathrm{Ru}^{\mathrm{III}}$ states, a solution of $1 \mathrm{mM} \mathrm{Ce} \mathrm{CII}^{\mathrm{III}}$ and $0.3 \mathrm{M} \mathrm{HNO}_{3}$, as well as a solution of $1 \mathrm{~mm} \mathrm{Ce} \mathrm{IV}^{\mathrm{IV}}$ and $0.3 \mathrm{M} \mathrm{HNO}_{3}$, were used, respectively. The amount of $\mathrm{Ru}(\mathrm{bpy})_{3}$ introduced into the microgels was calculated on the basis of ultraviolet visible measurements (Shimadzu UV-2500PC, Shimadzu, Kyoto, Japan). Absorbance at $460 \mathrm{~nm}$, which is the wavelength of the maximum absorbance for $\left[\mathrm{Ru}(\mathrm{bpy})_{3}\right]^{2+}$, of the microgels dispersed in pure water was determined to calculate the amount of $\mathrm{Ru}(\mathrm{bpy})_{3}$ monomer introduced into the microgels.

Optical transmittance data of self-oscillation were collected on a Shimadzu UV-2500PC spectrophotometer. Microgels were dispersed in an aqueous solution containing the reactants of the BZ reaction: malonic acid $(62.5 \mathrm{~mm})$, $\mathrm{NaBrO}_{3}(84 \mathrm{~mm})$ and $\mathrm{HNO}_{3}(0.3 \mathrm{M})$. Under constant temperature and stirring 
conditions, the time course of transmission was monitored. The $R u(b p y)_{3}$ complex has different absorption spectra in the reduced $\mathrm{Ru}^{\mathrm{II}}$ state and in the oxidized $\mathrm{Ru}^{\mathrm{III}}$ state as an inherent property. The solution exhibited absorption maximum at $\sim 460 \mathrm{~nm}$ in the reduced state, as well as at $\sim 420 \mathrm{~nm}$ in the oxidized state, and has an isosbestic point at $570 \mathrm{~nm}$. In this study, the $570 \mathrm{~nm}$ wavelength was selected to detect the swelling/deswelling signals of the microgels, whereas the $460 \mathrm{~nm}$ wavelength was used to detect the redox change of $\mathrm{Ru}(\mathrm{bpy})_{3}$ for the bulk solution of the $\mathrm{BZ}$ reaction as a control.

\section{RESULTS AND DISCUSSION}

Preparation and characterization of self-oscillating core/shell microgels

The synthesis of core microgels was carried out using NIPAm and $\mathrm{Ru}(\mathrm{bpy})_{3}$ monomers and the crosslinker by surfactant-free aqueous precipitation polymerization as previously reported. ${ }^{19-22}$ Using microgels as cores, seeded precipitation polymerization of NIPAm or NIPMAm was carried out. Figure 2 shows the temperature dependence of the hydrodynamic diameters for all microgels synthesized in this study. As shown in Figure 2a, comparing core and both core/shell microgels, increases in size both below and above VPTTs were observed for core/shell microgels. This result indicates that pNIPAm and pNIPMAm shells were indeed added to the core. In this study, the pNIPAm shell is thicker than the pNIPMAm shell, which is probably because of the difference in reactivity with the crosslinker; pNIPMAm might not be crosslinked effectively when they are added to the core microgels. Importantly, each dispersion of the microgels was determined to be monodispersed (calculated polydispersity indice values from DLS measurements were below 0.05 for all batches of microgels at all temperatures). Thereafter, we checked the temperature dependence of the hydrodynamic diameters in a $0.3 \mathrm{M} \mathrm{NaCl}$ solution (Figure $2 \mathrm{~b}$ ) because the BZ reaction only occurs at high salt concentrations $(>0.3 \mathrm{M})$. In contrast to the microgels dispersed in $\mathrm{NaCl}$ solutions of lower concentration $(0.01 \mathrm{M})$, as shown in Figure $2 \mathrm{a}$, all microgels flocculated above VPTTs in a $0.3 \mathrm{M} \mathrm{NaCl}$ solution, as shown in Figure 2b. Under this condition, the core microgels flocculated at $32{ }^{\circ} \mathrm{C}$ (=critical flocculation temperature, CFT), whereas the core/ pNIPAm and the core/pNIPMAm shell microgels flocculated at 31 and $39^{\circ} \mathrm{C}$, respectively. These changes in CFT are one of the proofs of shell addition. In general, pNIPAm-based microgels lose colloidal stability above the VPTT when they are dispersed in a salt solution of high concentration because colloidal stability is highly influenced by surface structures. The CFTs obtained here are slightly different than the lower critical solution temperatures of pNIPAm and pNIPMAm in pure water ( 31 and $44^{\circ} \mathrm{C}$, respectively). This difference may be related to differences in salt concentrations and to the lowered VPTT of the shell due to the deswelling of the core. ${ }^{28}$

Next, we checked the changes in hydrodynamic diameters between the reduced $\mathrm{Ru}^{\mathrm{II}}$ and the oxidized $\mathrm{Ru}^{\mathrm{III}}$ states. Figure 3 shows the temperature dependence of the hydrodynamic diameters in the reduced $\mathrm{Ru}^{\mathrm{II}}$ and oxidized $\mathrm{Ru}^{\mathrm{III}}$ states as measured by DLS. Here, each solution contains $0.3 \mathrm{M} \mathrm{HNO}_{3}$ because the $\mathrm{BZ}$ reaction only occurs at high salt concentrations. For core microgels, size deviations between the $\mathrm{Ru}^{\mathrm{II}}$ and $\mathrm{Ru}^{\mathrm{II}}$ states at the same temperatures are clearly seen from 15 to $31^{\circ} \mathrm{C}$ (Figure 3a). In addition, CFTs of the reduced $\mathrm{Ru}^{\mathrm{II}}$ and oxidized $\mathrm{Ru}^{\mathrm{III}}$ states ( 32 and $34^{\circ} \mathrm{C}$, respectively) differed because of the change in colloidal stability. After shell addition, size deviations between the $\mathrm{Ru}^{\mathrm{II}}$ and $\mathrm{Ru}^{\mathrm{III}}$ states at the same temperatures became smaller than that of the core microgel. This effect is due to core compression as a result of seeded precipitation polymerization: thus, the swelling ability of the core becomes smaller. ${ }^{24-28}$ In this study, the pNIPAm shell is thicker than the pNIPMAm shell. It has
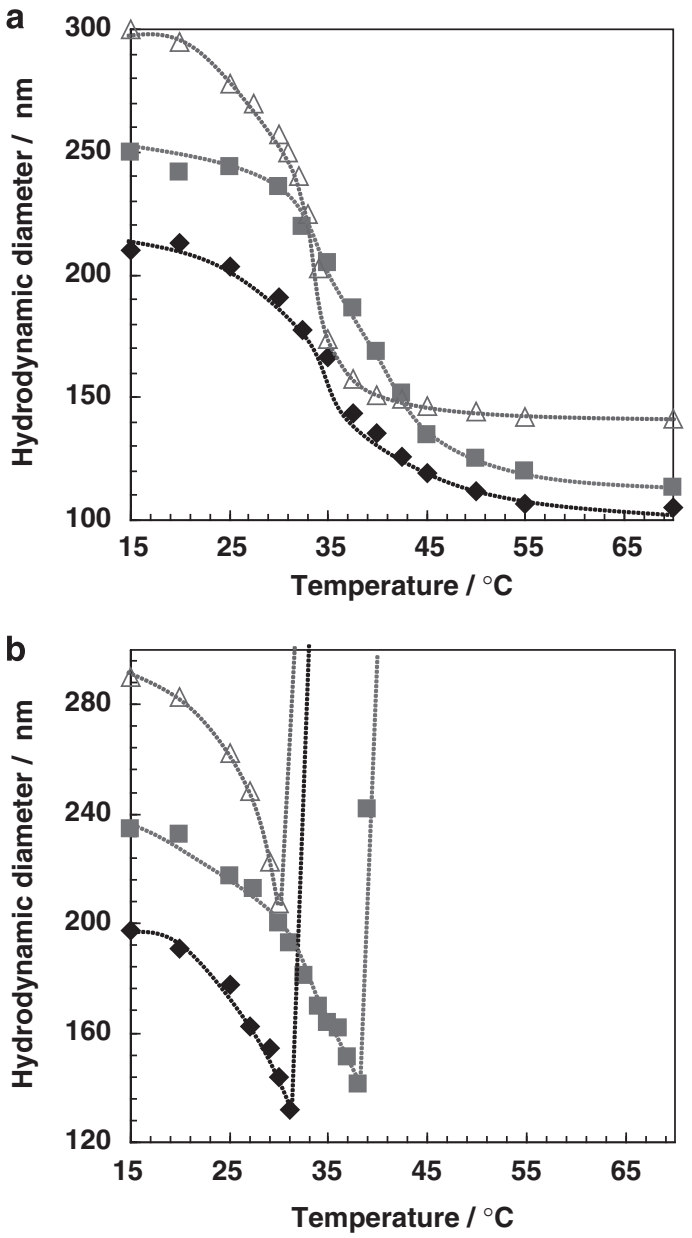

Figure 2 Temperature dependence of the hydrodynamic diameters of core (black diamond), core/pNIPAm shell (blue triangle) and core/pNIPMAm shell (red square) microgels as measured by DLS. Ionic strengths were 0.001 (a) and 0.3 (b). The dispersion concentration was 0.005 wt $\%$ in both cases. A full color version of this figure is available at the Polymer Journal journal online.

been thoroughly proven that the addition of thicker shells greatly restricts core swelling. ${ }^{31}$ Thus, the core/pNIPMAm shell microgel clearly showed size deviations at the same temperatures, whereas the core/pNIPAm shell microgel did not show quite as much. Most importantly, CFTs of the core/pNIPMAm shell microgel in both the $\mathrm{Ru}^{\mathrm{II}}$ and $\mathrm{Ru}{ }^{\mathrm{III}}$ states became higher $\left(38\right.$ and $39^{\circ} \mathrm{C}$, respectively) than that of the parent core microgels. However, the core/pNIPAm shell microgel did not show higher CFTs than the parent core microgel. These results suggest that the combination of chemical structures between the core and the shell is important to design the desired core/ shell microgels. In contrast to our expectations, these CFTs of the core/ shell microgels in the $\mathrm{Ru}^{\mathrm{II}}$ and $\mathrm{Ru}^{\mathrm{III}}$ states did not correspond to each other $\left(38\right.$ and $39^{\circ} \mathrm{C}$ for the core/pNIPMAm shell microgel and 31 and $32^{\circ} \mathrm{C}$ for the core/pNIPAm shell microgel, respectively). This fact suggests that the contraction of the core and/or electrostatic repulsion from the core may influence the colloidal stability of the core/shell microgels.

\section{Effect of nanoshell addition on oscillatory behavior}

To clarify the effect of the addition of a nanoshell on oscillatory behavior, we carried out the BZ reaction using core and core/shell microgels. In this investigation, malonic acid $(62.5 \mathrm{~mm}), \mathrm{NaBrO}_{3}$ 

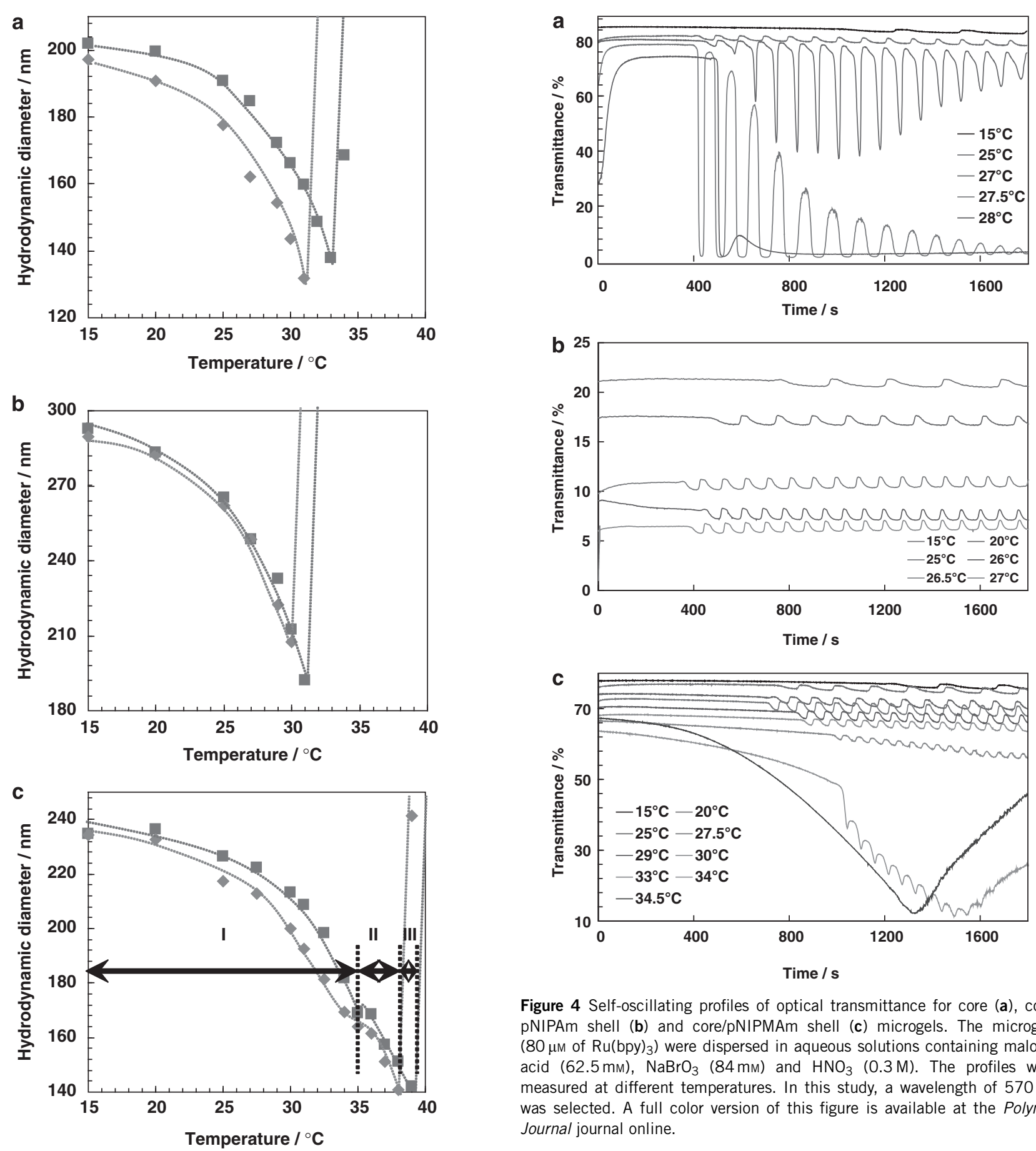

Figure 4 Self-oscillating profiles of optical transmittance for core (a), core/ pNIPAm shell (b) and core/pNIPMAm shell (c) microgels. The microgels $\left(80 \mu \mathrm{m}\right.$ of $\left.\mathrm{Ru}(\mathrm{bpy})_{3}\right)$ were dispersed in aqueous solutions containing malonic acid $(62.5 \mathrm{~mm}), \mathrm{NaBrO}_{3}(84 \mathrm{~mm})$ and $\mathrm{HNO}_{3}(0.3 \mathrm{M})$. The profiles were measured at different temperatures. In this study, a wavelength of $570 \mathrm{~nm}$ was selected. A full color version of this figure is available at the Polymer Journal journal online.

Figure 3 Temperature dependence of the hydrodynamic diameters of core (a), core/pNIPAm shell (b) and core/pNIPMAm shell (c) microgels under the reduced state $\mathrm{Ru}^{\prime \prime}$ in $1 \mathrm{~mm} \mathrm{Ce} \mathrm{ClI}^{\mathrm{III}}$ and $0.3 \mathrm{M} \mathrm{HNO}_{3}$ solution (orange diamond), as well as the oxidized state $\mathrm{Ru}^{\mathrm{III}}$ in $1 \mathrm{~mm} \mathrm{Ce} \mathrm{Cl}^{\mathrm{IV}}$ and $0.3 \mathrm{M} \mathrm{HNO}_{3}$ solution (green square) as measured by DLS. The dispersion concentration was 0.005 wt \% in all cases. I to III shown in Figure 3c correspond to those in Figure 5. A full color version of this figure is available at the Polymer Journal journal online.

( $84 \mathrm{~mm})$ and $\mathrm{HNO}_{3}(0.3 \mathrm{M})$ were used as substrates for the BZ reaction at fixed concentrations for all experiments. Figure 4 shows the temperature dependence of self-oscillating profiles of optical transmittance for core and core/shell microgel dispersions. For all

profiles, the oscillations were observed after an induction period, which is a typical characteristic of the $\mathrm{BZ}$ reaction. Note that we conducted these investigations by changing the temperature, whereas the other conditions were fixed (that is, initial concentrations of substrates, stirring and microgel concentrations) to compare the characteristics with each other, that is, the induction period, oscillating period and oscillating waveform. Figure $4 \mathrm{a}$ shows the oscillation profiles of transmittance for core microgel dispersions as a function of temperature. At low temperatures $\left(15-25^{\circ} \mathrm{C}\right)$, the amplitude of the oscillation became slightly greater with increasing temperatures (for example, $1.1 \%$ at $15^{\circ} \mathrm{C}$ and $1.8 \%$ at $25^{\circ} \mathrm{C}$ ). The increase in amplitude is mainly due to the increased deviation of the hydrodynamic 
diameters between the $\mathrm{Ru}^{\mathrm{II}}$ and $\mathrm{Ru}^{\mathrm{III}}$ states, as shown in Figure $3 \mathrm{a}$. Next, a remarkable change in waveform and amplitude was observed at $27^{\circ} \mathrm{C}$. The amplitude then attenuated at $27.5^{\circ} \mathrm{C}$. The periodic transmittance changes could no longer be observed at higher temperatures because of the flocculation of microgels. We had observed these phenomena previously; the dramatic change in oscillating waveform and amplitude is related to the difference in colloidal stability between the $\mathrm{Ru}^{\mathrm{II}}$ and $\mathrm{Ru}^{\mathrm{III}}$ states. The difference led to the autonomous flocculating/dispersing oscillation of the microgels. ${ }^{19}$ On the other hand, such a dramatic change in amplitude was not observed for the core/shell microgels, as shown in Figures $4 \mathrm{~b}$ and c. For the core/ pNIPAm microgels shown in Figure $4 \mathrm{~b}$, the amplitudes of oscillation were not very different between 15 and $27^{\circ} \mathrm{C}$, which should be because of small deviations in size between the $\mathrm{Ru}^{\mathrm{II}}$ and $\mathrm{Ru}^{\mathrm{III}}$ states at all temperatures $\left(0.7 \%\right.$ at $15^{\circ} \mathrm{C}, 0.8 \%$ at $20^{\circ} \mathrm{C}, 0.8 \%$ at $25^{\circ} \mathrm{C}, 0.8 \%$ at $26.5^{\circ} \mathrm{C}$ and $0.7 \%$ at $27^{\circ} \mathrm{C}$ ). The periodic transmittance changes could no longer be observed at higher temperatures because of the flocculation of microgels. For the core/pNIPMAm microgels shown in Figure $4 \mathrm{c}$, the oscillatory behavior as a function of temperature was different from that of core/pNIPAm microgels. The amplitudes of oscillation became slightly greater with increasing temperature from 15 to $29^{\circ} \mathrm{C}\left(1.2 \%\right.$ at $15^{\circ} \mathrm{C}, 1.3 \%$ at $20^{\circ} \mathrm{C}, 1.9 \%$ at $25^{\circ} \mathrm{C}, 2.7 \%$ at $27.5^{\circ} \mathrm{C}, 2.7 \%$ at $29^{\circ} \mathrm{C}$ ) and then became slightly smaller from 30 to $33{ }^{\circ} \mathrm{C}\left(1.7 \%\right.$ at $30^{\circ} \mathrm{C}$ and $1.5 \%$ at $\left.33^{\circ} \mathrm{C}\right)$. The increase in amplitude at low temperatures is mainly due to the increased deviation of the hydrodynamic diameters between the $\mathrm{Ru}^{\mathrm{II}}$ and $\mathrm{Ru}^{\mathrm{III}}$ states, as shown in Figure 3c, which is the same reason for the behavior of the core microgels. However, the decrease in amplitude is a new phenomenon, which should be related to smaller deviations in size between the $\mathrm{Ru}^{\mathrm{II}}$ and $\mathrm{Ru}^{\mathrm{III}}$ states at higher temperatures, as shown in Figure $3 \mathrm{c}$. After that, an increased amplitude with a decreased total transmittance was observed at $34^{\circ} \mathrm{C}$, which may be due to autonomous dispersing/ flocculating oscillation of microgels. ${ }^{19}$ A possible oscillating mechanism of the core/pNIPMAm microgels is illustrated in Figure 5. At low temperatures (region I, Figures $3 c$ and 5), the amplitude of the swelling/deswelling oscillation increases with temperature because of increases in size deviation, as can be seen in Figure 3c. The amplitude then decreases with rising temperature because the core is largely deswollen; thus, the size deviations between the $\mathrm{Ru}^{\mathrm{II}}$ and $\mathrm{Ru}^{\mathrm{III}}$ states measured by DLS become almost the same (region II, Figures $3 \mathrm{c}$ and 5). Thereafter, the oscillatory amplitude increases, but the total transmittance decreases because of the autonomous dispersing/ flocculating oscillation (region III, Figures $3 \mathrm{c}$ and 5 ). ${ }^{19}$ In this region III, the core part should be completely deswollen. Thus, the autonomous dispersing/flocculating oscillation of the core/pNIPMAm shell microgels indicates that the charge density originating from the core may contribute to the colloidal stability of the microgels.

We next compared the oscillations of the microgels with the bulk solution of the $\mathrm{BZ}$ reaction in terms of the induction period. It should be noted that we did not use the core/pNIPAm microgels further because the core/shell microgels did not show desirable properties. Figure 6 shows the temperature dependence of the induction periods of the microgel oscillations and the bulk solution of the BZ reaction. It is to be noted that the induction periods for the microgels could not be measured above the CFTs of the microgels because of flocculation. The induction period for both core and core/pNIPMAm shell microgels became longer than that of the bulk solution of the BZ reaction in this temperature range. Moreover, the induction period for core/ pNIPMAm microgels became longer than that of core microgels at all temperatures. In particular, the induction period for core/pNIPMAm microgels increased with temperatures above $27.5^{\circ} \mathrm{C}$. The most accepted hypothesis to explain the induction period of the $\mathrm{BZ}$ reaction is that a crucial concentration of the organic brominated species, mainly bromomalonic acid, must be reached before oscillation begins. ${ }^{32}$ Thus, the results in Figure 6 can be understood by the effect

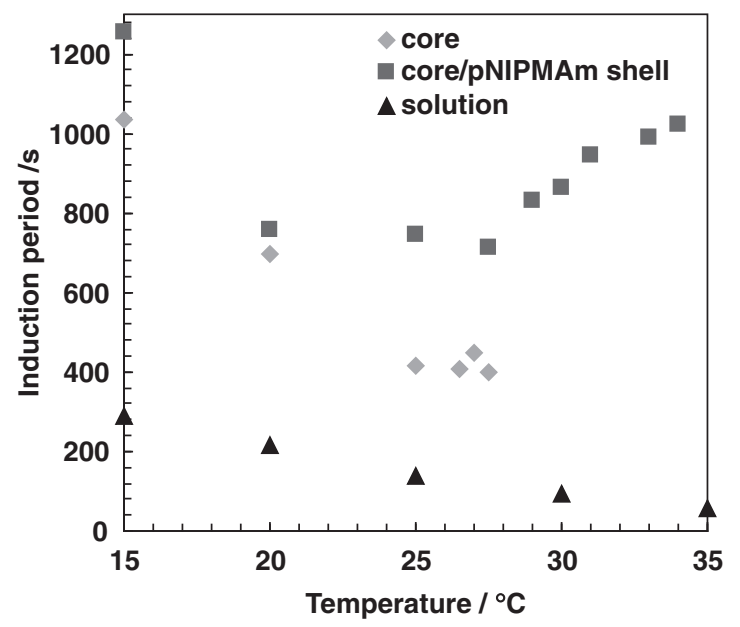

Figure 6 Effect of temperature on the duration of the induction period for the bulk solution of the BZ reaction as a control (black triangle), as well as for core (red diamond) and the core/pNIPMAm shell (blue square) microgels. The microgels $\left(80 \mu \mathrm{m} R(\mathrm{bpy})_{3}\right)$ were dispersed in aqueous solutions containing malonic acid $(62.5 \mathrm{~mm}), \mathrm{NaBrO}_{3}(84 \mathrm{~mm})$ and $\mathrm{HNO}_{3}(0.3 \mathrm{~m})$. A full color version of this figure is available at the Polymer Journal journal online.
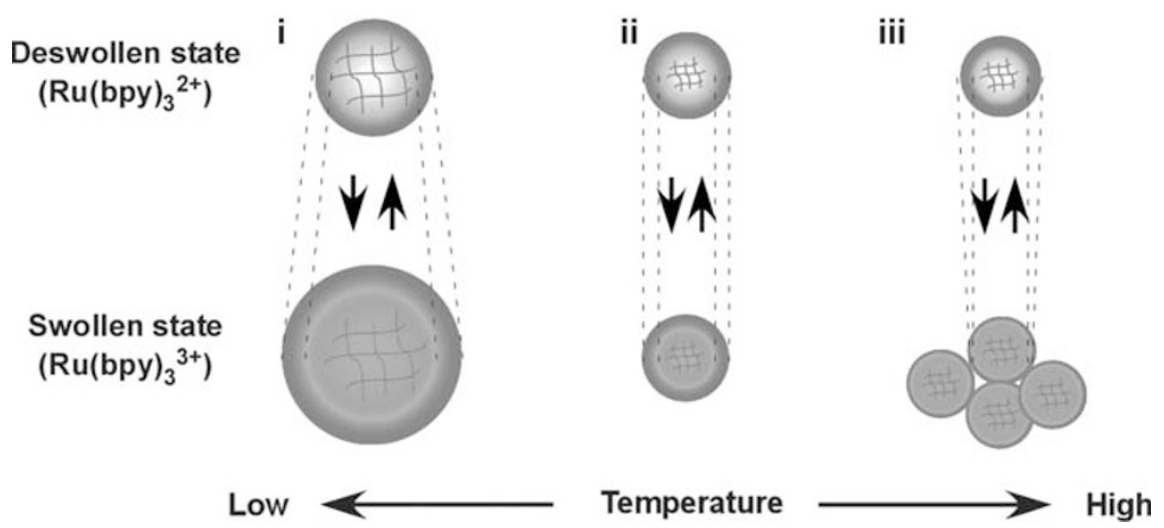

Figure 5 Different oscillating modes for core/shell microgels. I-III shown here correspond to those in Figure 3c. A full color version of this figure is available at the Polymer Journal journal online. 


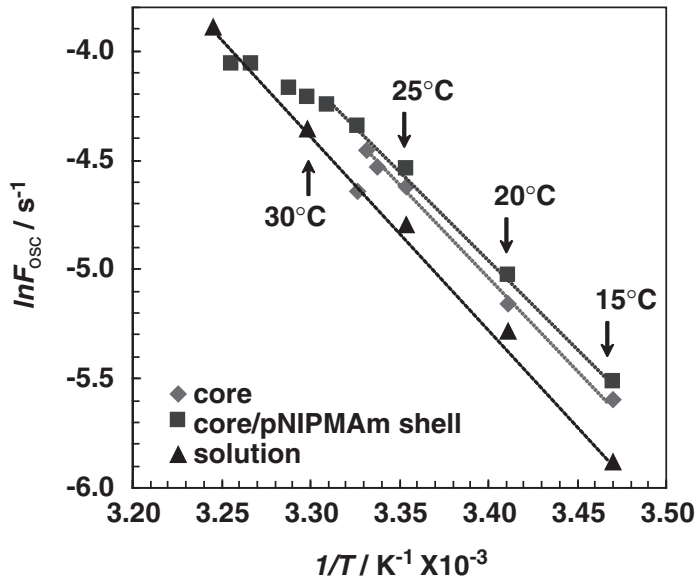

Figure 7 Arrhenius dependence of oscillating frequency $\left(F_{\text {osc }}\right)$ using core (red diamond) and core/pNIPMAm shell (blue square) microgels. Microgels $\left(80 \mu \mathrm{M} \mathrm{Ru}(\mathrm{bpy})_{3}\right)$ were dispersed in aqueous solutions containing malonic acid $(62.5 \mathrm{~mm}), \mathrm{NaBrO}_{3}(84 \mathrm{~mm})$ and $\mathrm{HNO}_{3}(0.3 \mathrm{M})$. Control experiments of the $B Z$ reaction without microgels were investigated (black triangle) in the same aqueous solution. A full color version of this figure is available at the Polymer Journal journal online.

of $\mathrm{Ru}(\mathrm{bpy})_{3}$ immobilization in the microgels, which is similar to the hydrogel-immobilized enzyme reaction. ${ }^{33}$ In the microgel systems described in this study, the rate of bromomalonic acid production is lower than that of the bulk solution of the $\mathrm{BZ}$ reaction because of the lower diffusion constant of substrates and intermediates in the microgels. In addition, the diffusion constant of the substrates and intermediates in the core/shell microgels is lower than that in the parent core microgels. In particular, the diffusion constant should be very low when the core/pNIPMAm shell is highly deswollen (that is, above $27.5^{\circ} \mathrm{C}$ ). This result is one of the proofs of the addition of shells to the parent core.

We then compared the oscillations of microgels with the bulk solution of the $\mathrm{BZ}$ reaction in terms of the oscillation period, $P_{\mathrm{osc}}$. In this study, the average value of the period between the second and the sixth oscillation was regarded as the oscillation period. Because our measurements of oscillations were completed after a small percentage of the initial quantity of the substrates was consumed, the concentration of the substrate at a specific measuring time may be approximated as its initial concentration. Here, the frequency of the oscillation, $F_{\text {osc }}\left(F_{\text {osc }}=1 / P_{\text {osc }}\right)$, was used for analysis. As shown in Figure 7 , the frequency of the bulk solution for the $\mathrm{BZ}$ reaction increased with temperature, in accordance with the Arrhenius equation. ${ }^{34}$ For core microgels, the Arrhenius equation could be fitted in the case in which the temperature was below the VPTT, as shown in Figure 7. However, the frequency decreased near the VPTT of the microgels because of the autonomous dispersing/flocculating oscillation, and the corresponding plots deviated from the Arrhenius equation, which agrees with our previous data. ${ }^{20}$ For core/pNIPMAm shell microgels, the Arrhenius equation could be fitted when the temperature was above the VPTT of the parent core microgels (up to $29^{\circ} \mathrm{C}$ ). Above $29^{\circ} \mathrm{C}$, the plots deviate slightly from the Arrhenius equation before the flocculation of microgels. These deviations both for the core and core/pNIPMAm shell microgels may be related to the lowered diffusibility of the substrates and intermediates in the microgels; the diffusion constant should be lower in highly deswollen aggregates of the core microgels, whereas the constant should be lower without aggregation of the core/pNIPMAm shell microgels, that is, the simple deswelling of the core/shell microgels. In addition, the frequency for the core/pNIPMAm shell microgels became higher than that for the parent core between 15 and $25^{\circ} \mathrm{C}$. We have already reported that the frequency increased as the crosslinked density of the microgels increased when they are in the swollen state. ${ }^{20}$ Thus, in this study, higher frequencies for core/pNIPMAm shell microgels may be because of greater difficulties in mass transportation in the core/ shell microgel than in the parent core. In conclusion, the structure of the microgel has an important role in controlling the oscillation frequency.

Next, to understand the effect of the addition of the nanoshell to parent core microgels on the oscillation period in more detail, we compared the representative waveforms observed for the core microgels and the core/pNIPMAm shell microgels (Figure 8). Before comparing these waveforms, we will provide the outline of the Field-Körös-Noyes mechanism. ${ }^{35,36}$ According to this scheme, the overall BZ reaction may be divided into the following three main processes: the consumption of the bromide ion (process $A$ ), the autocatalytic reaction of the bromous acid with oxidation of the catalyst (process $\mathrm{B}$ ) and the organic reaction with reduction of the catalyst (process C).

$$
\begin{aligned}
& \text { A : } \mathrm{BrO}_{3}^{-}+2 \mathrm{Br}^{-}+3 \mathrm{H}^{+} \rightarrow 3 \mathrm{HOBr} \\
& \mathrm{B}: \mathrm{BrO}_{3}^{-}+\mathrm{HBrO}_{2}+2 \mathrm{M}_{\mathrm{red}}+3 \mathrm{H}^{+} \rightarrow 2 \mathrm{HBrO}_{2}+2 \mathrm{M}_{\mathrm{ox}}+\mathrm{H}_{2} \mathrm{O} \\
& \mathrm{C}: 2 \mathrm{M}_{\mathrm{ox}}+\mathrm{MA}+\mathrm{BrMA} \rightarrow \mathrm{fBr}^{-}+2 \mathrm{M}_{\mathrm{red}}+\text { other products }
\end{aligned}
$$

Following the Field-Körös-Noyes mechanism, we divided the waveforms into processes $\mathrm{A}, \mathrm{B}$ and $\mathrm{C}$, as shown in Figure 8. Table 1 summarizes the oscillating periods $P_{\mathrm{osc}}$, the durations of processes $\mathrm{A}-\mathrm{C}$, as well as the $A / P_{\text {osc }}, B / P_{\text {osc }}$ and $C / P_{\text {osc }}$ values for the bulk solution, the core microgels and the core/pNIPMAm shell microgels. At the same temperatures, the $B / P_{\text {osc }}$ and $C / P_{\text {osc }}$ values for the microgel systems became larger than those for the bulk solution. Moreover, these values for the core/pNIPMAm shell microgels became larger than those of the parent core microgels at the same temperatures. We have already reported that the change in oscillating rhythm between the bulk solution and microgels can also be understood from the effect of $\mathrm{Ru}(\mathrm{bpy})_{3}$ immobilization in the microgels because processes $\mathrm{B}$ and $\mathrm{C}$ contain a catalytic reaction; the rate of an immobilized catalytic reaction is lower than that of the same amount of a soluble catalyst. ${ }^{20}$ In this study, we found that shell addition affected the rhythm of oscillation further because of greater difficulties in mass transportation in core/pNIPMAm shell microgels than in the parent core. In contrast, the $A / P_{\text {osc }}$ values for microgels became smaller than those for the bulk solution at the same temperatures. The values for core/pNIPMAm shell microgels also became smaller than that for the parent core at the same temperatures. The smaller $A / P_{\text {osc }}$ values of microgels may be related to their larger $C / P_{\text {osc }}$ values; the lowered rate of process $\mathrm{C}$ may affect process $\mathrm{A} .{ }^{21}$ As a result, we found that changes in the oscillation period between core and core/ pNIPMAm shell microgels were due to a similar effect on the dependence of the crosslinking density as previously reported; that is, mass transportation in microgels has an important role in determining the oscillatory behavior.

\section{CONCLUSIONS}

We synthesized self-oscillating core/shell microgels by precipitation polymerization. Compared with parent core microgels, the flocculation temperature for core/pNIPMAm shell microgels increased, resulting in a new oscillating mode, which is supported by changes in the 
a

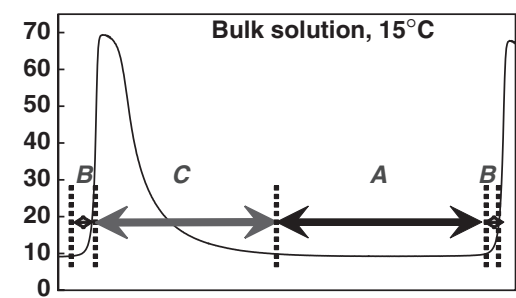

b
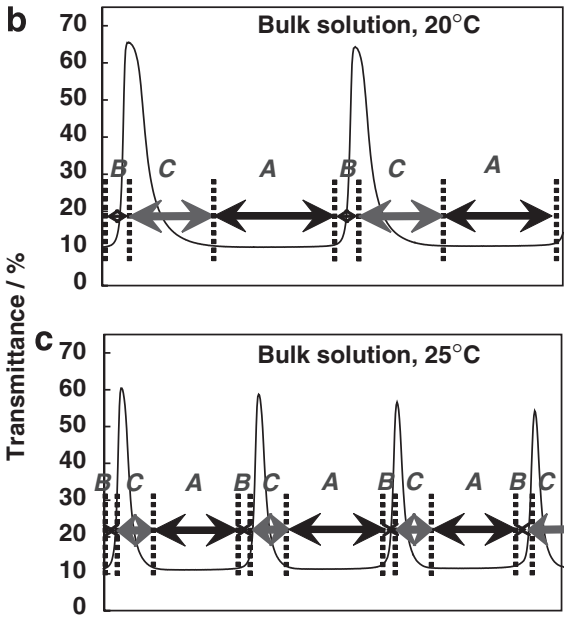

d

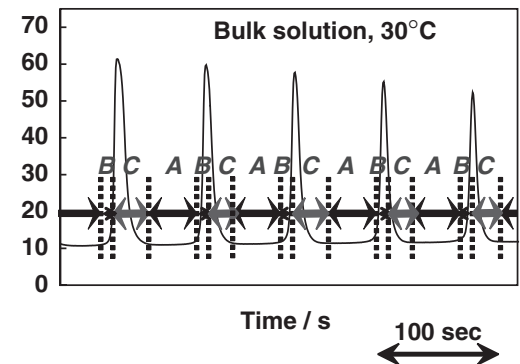

e 78
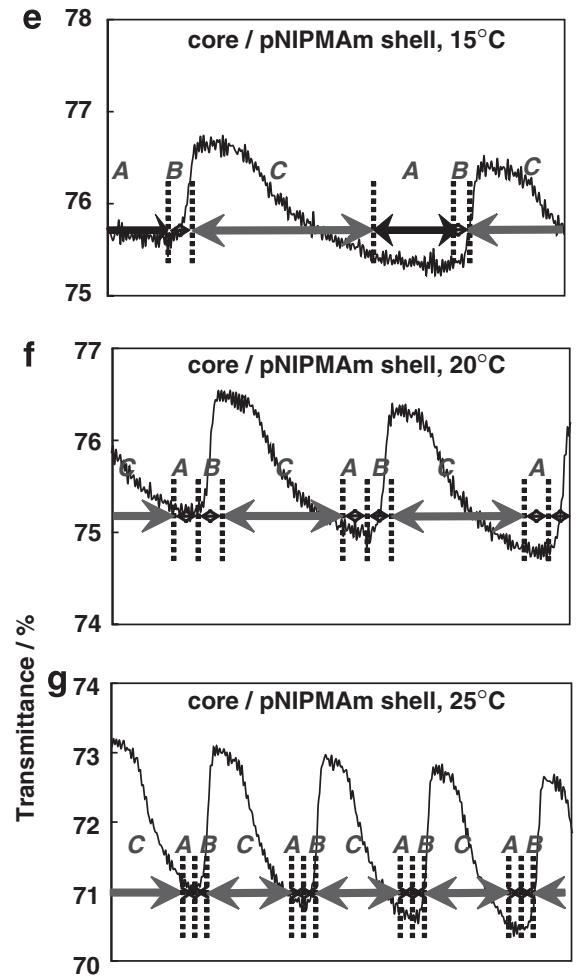

h

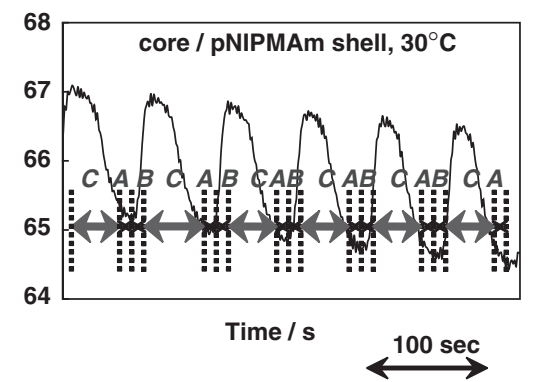

Figure 8 Typical oscillating waveforms in the bulk solution of the BZ reaction (a-d) and in core/pNIPMAm shell microgels (e-h). Microgels $\left.(80 \mu \mathrm{m} \text { Ru(bpy) })_{3}\right)$ were dispersed in aqueous solutions containing malonic acid $(62.5 \mathrm{~mm}), \mathrm{NaBrO}_{3}(84 \mathrm{~mm})$ and $\mathrm{HNO}_{3}(0.3 \mathrm{~m})$. The profiles were measured at different temperatures: $15^{\circ} \mathrm{C}(\mathbf{a}, \mathbf{e}), 20^{\circ} \mathrm{C}(\mathbf{b}, \mathbf{f}), 25^{\circ} \mathrm{C}(\mathbf{c}, \mathbf{g})$ and $30^{\circ} \mathrm{C}(\mathbf{d}, \mathbf{h})$. Control experiments of the $\mathrm{BZ}$ reaction without microgels were investigated in the same

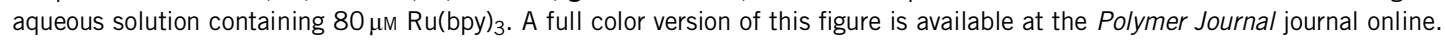

Table $1 A / P_{\mathrm{OSc}}, B / P_{\mathrm{OSC}}$ and $C / P_{\mathrm{OSC}}$ values for the bulk solution of the $\mathrm{BZ}$ reaction, the core and the core/pNIPMAm shell microgel systems

\begin{tabular}{lccccccc}
\hline Sample & Temp., ${ }^{\circ} \mathrm{C}$ & $P_{\text {osc }}, s$ & $A, s$ & $B, s$ & $C, s$ & $A / P_{\text {osc }}$ & B/Posc \\
\hline Bulk solution & 15 & 357 & 183 & 18 & 155 & 0.51 & 0.05 \\
Bulk solution & 20 & 197 & 111 & 17 & 69 & 0.56 & 0.09 \\
Bulk solution & 25 & 120 & 70 & 14 & 37 & 0.58 & 0.11 \\
Bulk solution & 30 & 77 & 41 & 11 & 26 & 0.53 & 0.13 \\
Core/pNIPMAm shell & 15 & 248 & 78 & 16 & 154 & 0.31 & 0.35 \\
Core/pNIPMAm shell & 20 & 152 & 27 & 19 & 106 & 0.18 & 0.13 \\
Core/pNIPMAm shell & 25 & 96 & 11 & 16 & 69 & 0.11 & 0.17 \\
Core/pNIPMAm shell & 30 & 71 & 9 & 13 & 49 & 0.13 & 0.18 \\
Core & 15 & 273 & 103 & 18 & 152 & 0.38 & 0.73 \\
Core & 20 & 177 & 45 & 15 & 117 & 0.25 & 0.07 \\
Core & 25 & 103 & 27 & 13 & 63 & 0.26 & 0.08 \\
\hline
\end{tabular}

induction period, the amplitude of oscillation, the oscillating period and the oscillating waveforms. We believe that this material will enable us to create new technologies including microactuators for use in microfluidic devices.

\section{ACKNOWLEDGEMENTS}

DS gratefully acknowledges the Grant-in-Aid for Young Scientists (Start-up) from the Ministry of Education, Culture, Sports, Science, and Technology of Japan (21850014). 
1 Hirokawa, Y. \& Tanaka, T. Volume phase-transition in a nonionic gel. J. Chem. Phys. 81, 6379 (1984).

2 Kawasaki, H., Sasaki, S. \& Maeda, H. Effect of $\mathrm{pH}$ on the volume phase transition of copolymer gels of $\mathrm{N}$-isopropylacrylamide and sodium acrylate. J. Phys. Chem. B. 101, 5089 (1997).

3 Snowden, M. J., Chowdhry, B. Z., Vincent, B. \& Morris, G. E. Colloidal copolymer microgels of $\mathrm{N}$-isopropylacrylamide and acrylic acid: $\mathrm{pH}$, ionic strength and temperature effects. J. Chem. Soc. Faraday Trans. 92, 5013 (1996).

4 Sershen, S. R., Westcott, S. L., Halas, N. J. \& West, J. L. Temperature-sensitive polymer-nanoshell composites for photothermally modulated drug delivery. J. Biomed. Mater. Res. 51, 293 (2000).

5 Heskins, M. \& Guillet, J. E. Solution properties of poly( $N$-isopropylacrylamide). J. Macromol. Sci. Part A 2, 1441 (1968).

6 Schild, H. G. Poly ( $N$-isopropylacrylamide)-experiment, theory and application. Prog. Polym. Sci. 17, 163 (1992).

7 Suzuki, D. \& Kawaguchi, H. Modification of gold nanoparticle composite nanostructures using thermosensitive core-shell particles as a template. Langmuir 21, 8175 (2005).

8 Suzuki, D. \& Kawaguchi, H. Gold nanoparticle localization at the core surface by using thermosensitive core-shell particles as a template. Langmuir 21, 12016 (2005).

9 Suzuki, D. \& Kawaguchi, H. Hybrid microgels with reversibly changeable multiple brilliant color. Langmuir 22, 3818 (2006).

10 Suzuki, D. \& Kawaguchi, H. Stimuli-sensitive core/shell template particles for immobilizing inorganic nanoparticles in the core. Colloid Polym. Sci. 284, 1443 (2006).

11 Hsiue, G. H., Hsu, S. H., Yang, C. C., Lee, S. H. \& Yang, I. K. Preparation of controlled release ophthalmic drops, for glaucoma therapy using thermosensitive poly- $\mathrm{N}$-isopropylacrylamide. Biomaterials 23, 457 (2002).

12 Nayak, S., Lee, H., Chmielewski, J. \& Lyon, L. A. Folate-mediated cell targeting and cytotoxicity using thermoresponsive microgels. J. Am. Chem. Soc. 126, 10258 (2004).

13 Morris, G. E., Vincent, B. \& Snowden, M. J. Adsorption of lead ions onto $\mathrm{N}$ isopropylacrylamide and acrylic acid copolymer microgels. J. Colloid Interface Sci. 190, 198 (1997).

14 Kawaguchi, H., Kisara, K., Takahashi, T., Achiha, K., Yasui, M. \& Fujimoto, K. Versatility of thermosensitive particles. Macromol. Symp. 151, 591 (2000).

15 Weissman, J. M., Sunkara, H. B., Tse, A. S. \& Asher, S. A. Thermally switchable periodicities and diffraction from mesoscopically ordered materials. Science $\mathbf{2 7 4}, 959$ (1996).

16 Suzuki, D., McGrath, J. G., Kawaguchi, H. \& Lyon, L. A. Colloidal crystals of thermosensitive, core/shell hybrid microgels. J. Phys. Chem. C 111, 5667 (2007).

17 Lyon, L. A., Debord, J. D., Debord, S. B., Jones, C. D., McGrath, J. G. \& Serpe, M. J. Microgel colloidal crystals. J. Phys. Chem. B 108, 19099 (2004).
18 Tsuji, S . \& Kawaguchi, H. Colored thin films prepared from hydrogel microspheres. Langmuir 21, 8439 (2005).

19 Suzuki, D., Sakai, T. \& Yoshida, R. Self-flocculating/self-dispersing oscillation of microgels. Angew. Chem. Int. Ed 47, 917 (2008).

20 Suzuki, D. \& Yoshida, R. Temporal control of self-oscillation for microgels by crosslinking network structure. Macromolecules 41, 5830 (2008)

21 Suzuki, D. \& Yoshida, R. Effect of initial substrate concentration of the belousovzhabotinsky reaction on self-oscillation for microgel system. J. Phys. Chem. B 40, 12618 (2008).

22 Suzuki, D., Taniguchi, H. \& Yoshida, R. Autonomously oscillating viscosity in microgel dispersions. J. Am. Chem. Soc. 131, 12058 (2009).

23 Zaikin, A. N. \& Zhabotinsky, A. M. Concentration wave propagation in two-dimensional liquid-phase self-oscillating system. Nature 225, 535 (1970).

24 Jones, C. D. \& Lyon, L. A. Synthesis and characterization of multiresponsive core-shell microgels. Macromolecules 33, 8301 (2000).

25 Nayak, S., Gan, D., Serpe, M. J. \& Lyon, L. A. Hollow thermoresponsive microgels. Small 1, 416 (2005)

26 Nayak, S. \& Lyon, L. A. Ligand-functionalized core/shell microgels with permselective shells. Angew. Chem., Int. Ed. 43, 6706 (2004).

27 Berndt, I., Pedersen, J. S. \& Richtering, W. Structure of multiresponsive 'intelligent' core-shell microgels. J. Am. Chem. Soc. 127, 9372 (2005).

28 Berndt, I., Skov Pedersen, J. \& Richtering, W. Temperature-sensitive core-shell microgel particles with dense shell. Angew. Chem. Int. Ed. 45, 1737 (2006).

29 Yoshida, R., Takahashi, T., Yamaguchi, T. \& Ichijo, H. Self-oscillating gel. J. Am. Chem. Soc. 118, 5134 (1996).

30 Ghosh, P. K. \& Spiro, T. G. Photoelectrochemistry of tris(bipyridyl)ruthenium(II) covalently attached to n-type Tin(IV) oxide. J. Am. Chem. Soc. 102, 5543 (1980).

31 Jones, C. D. \& Lyon, L. A. Dependence of shell thickness on core compression in acrylic acid modified poly( $\mathrm{N}$-isopropylacrylamide) core/shell microgels. Langmuir 19, 4544 (2003).

32 Sirimungkala, A., Forsterling, H. D., Dlask, V. \& Field, R. J. Bromination reactions important in the mechanism of the Belousov-Zhabotinsky system. J. Phys. Chem. A 103, 1038 (1999).

33 Kokufuta, E. Functional immobilized biocatalysts. Prog. Polym. Sci. 17, 647 (1992).

34 Ruoff, P. Antagonistic balance in the oregonator-about the possibility of temperaturecompensation in the Belousov-Zhabotinsky reaction. Physica D 84, 204 (1995).

35 Field, R. J., Körös, E. \& Noyes, R. M. Oscillations in chemical systems. II. Thorough analysis of temporal oscillation in the bromate-cerium-malonic acid system. J. Am. Chem. Soc. 94, 8649 (1972).

36 Field, R. J. \& Noyes, R. M. Oscillations in chemical systems. IV. Limit cycle behavior in a model of a real chemical-reaction. J. Chem. Phys. 60, 1877 (1974). 